\title{
Design and Simulation of SEPIC Converter with Fuzzy-logic MPPT for Standalone System
}

\author{
Sudharsan V N ${ }^{1} \mid$ Dr.K. Ranjith Kumar ${ }^{2} \mid$ Rahulkumar J ${ }^{3}$ \\ ${ }^{1}$ Electrical and Electronics Department,Government College of Technology Coimbatore. \\ ${ }^{2}$ Professor, Electrical and Electronics Department, Government College of Technology Coimbatore. \\ ${ }^{3}$ Assistant Professor, Electrical and Electronics Department, Dr.NGP institute of Technology Coimbatore.
}

\section{To Cite this Article}

Sudharsan V N, Dr.K. Ranjith Kumar and Rahulkumar J, "Design and Simulation of SEPIC Converter with Fuzzy-logic MPPT for Standalone System", International Journal for Modern Trends in Science and Technology, 6(8): 112-119, 2020.

\section{Article Info}

Received on 23-June-2020, Revised on 14-July-2020, Accepted on 30-July-2020, Published on 07-August-2020.

\section{ABSTRACT}

This Paper establishes the system of Solar fed independent systems with a SEPIC converter with Dual Input and Dual output. The Maximum power point tracking of solar has been achieved by Fuzzy-logic Control method. The Control scheme implemented in this helps to extract maximum power effectively. The various suitable operations of converter have been achieved through Real time simulator (RTDS) and the outcomes are highlighted.

KEYWORDS: Dual Input-Dual Output; SEPIC Converter; Fuzzy-Logic Control_ MPPT; Solar PV Stand-alone system

\section{INTRODUCTION}

The various affordable renewable energy sources like solar, wind, Bio-Fuels and other would help in the production of electrical power in minimum scale as well as the large scale. This renewable system is capable of replacing the system powered from other non-conventional energy sources. The solar power generation is used in large scale because of its individual advantages like easy installation, maintenance free, cost efficient etc. The solar is considered as the abundant power generating source because the electricity from the solar panel is obtained by converting light energy. The solar power source plays a vital role in various applications like Satellites, defense hubs and remote places. The solar photo voltaic system is generally made up of semiconducting materials like silicon, according the doping and materials used the type of solar cell is categorized. They are classified as Monocrystalline, Polycrystalline, and Thin-Film. Each solar cell has their own efficiency. According to cost and availability the material is chosen. There are a lot of advancements are in progress to increase the efficiency of the material. The rapid emerging of solar cell types is Organic solar cell (OPV), Bio hybrid solar cell (BH-PV), Quantum dot solar cell. Each solar panel is rated to produce certain power that is given by maximum power $\left(\mathrm{P}_{\max }\right)$ and rated voltage $\left(\mathrm{V}_{\mathrm{oc}}\right)$, and Maximum current output $\left(\mathrm{I}_{\max }\right)$ all these parameters depends on the property of the material used and total number of cells in an array. The output power of solar is variable in nature due to its dependency towards sunlight, so there is a requirement of implementing a Maximum power point tracking technique to interface the source and the converter. This MPPT algorithm are of various types like, perturbation and observation $(\mathrm{P} \& \mathrm{O})$, 
Incremental conductance, Ripple Correlation technique, Constant Voltage method, Fractional open circuit method are some of the majorly used algorithms. Nowadays the artificial Intelligence plays a vital role in improving the efficiency of algorithms they are Fuzzy logic, artificial neural network, Artificial intelligence-based Particle swarm optimization, genetic algorithm and proportional integral derivatives and so on. In this paper the Fuzzy logic based MPPT is being implemented for a standalone power modulating converter.

\section{PROPOUNDED TOTAL SYSTEM AND DESIGN OPERATION}

In this propounded system for a solar based stand-alone system that uses Fuzzy algorithm for achieving MPPT and a SEPIC based DC-DC converter is designed. Here the stability of the system is improved by using an energy storage technology. The system is balanced when the requirement of the load is achieved in an undisturbed manner. The Dual Input and Dual output (DIDO) operation of the SEPIC converter helps the system to achieve balanced power flow to the load.

The Block diagram represents the total system and the energy flow of the autonomous system.

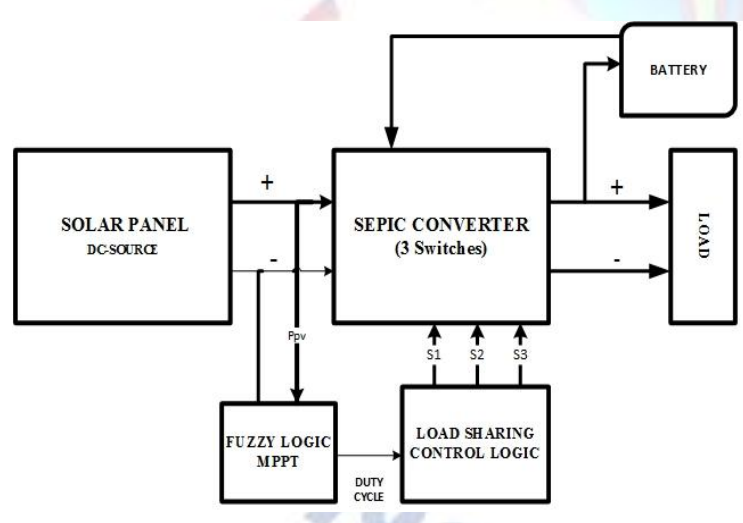

Fig 1 Block diagram of stand-alone system

\section{A. Solar Photovoltaic array (SPV ARRAY)}

The solar photo voltaic is an electronic device that directly converts the light into electricity. The photons absorbing semiconductor material can potentially satisfy the need of conversion [1]. The various solar array material gives variations in efficiency. Hence certain rating, material, and some electrical parameters are being considered while selecting them as a source. The panel is represented with various parameters such as
Irradiance $\left(\mathrm{i}_{\mathrm{rr}}\right)$, Open circuit Voltage $\left(\mathrm{V}_{\mathrm{oc}}\right)$, Short circuit current $\left(\mathrm{I}_{\mathrm{sc}}\right)$, Maximum Current $\left(\mathrm{I}_{\max }\right)$ are some of the parameters to be considered. The intrinsic properties of the cells are responsible for the generation of electric energy. In this work temperature is fixed to 25 degree Celsius that is the optimum temperature for the panel. To increase the power generation, according to demand certain additional panels are added in series resulting in voltage raise and higher power production. The Total power of the system is calculated by summing up of maximum power output $\left(\mathrm{P}_{\max }\right)$ from each panel or array.

Some of the values are given below that are used in simulation platform.

\begin{tabular}{|c|c|}
\hline Parameter & Specification \\
\hline Irradiation $\left(\mathrm{I}_{\mathrm{rr}}\right)$ & $1000 \mathrm{~W} / \mathrm{m}^{2}$ \\
\hline Open circuit voltage $\left(\mathrm{V}_{\mathrm{oc}}\right)$ & $26 \mathrm{~V}$ \\
\hline Short Circuit Voltage $\left(\mathrm{I}_{\mathrm{sc}}\right)$ & $5 \mathrm{~A}$ \\
\hline $\begin{array}{c}\text { Current at maximum power }(\mathrm{I} \\
\text { max }\end{array}$ & $4.95 \mathrm{~A}$ \\
\hline $\begin{array}{c}\text { Voltage at maximum power }\left(\mathrm{V}_{\mathrm{max}}\right) \\
\text { No of parallel strings }\end{array}$ & $25 \mathrm{~V}$ \\
\hline Series modules/ strings & 1 \\
\hline
\end{tabular}

Table

1 Parameters of solar panel

\section{B. Maximum Power point tracking}

The Maximum power point tracking (MPPT) are generally used to track maximum power, from the PV. The MPPT helps in impedance matching between the PV array and the load [2]. There are two classifications such as direct method and indirect method. Some of the methods that are being followed to obtain MPPT are Perturb and observe $(\mathrm{P} \& \mathrm{O})$ technique, adaptive hill climbing method, Particle swarm optimization (PSO) iterative heuristic global optimization algorithm and so on. In this paper Fuzzy based MPPT is proposed and simulated in real-time. The temperature and irradiance are given to the Fuzzy controller and output as control duty cycle to the converter [3]. Random variables of irradiance and temperature is given as the input to the fuzzy block. The fuzzy logic control is processed by three consecutive steps, namely Fuzzification, Inference of rules or rule evaluation and defuzzification. The fuzzification is done by taking raw data like open circuit voltage, change in voltage with respect to 
time and those are matched to the stored membership function to make it fuzzified. When the membership functions are declared the raw input, vales are taken in to consideration and present consecutive values are processed. The next step deals with the rule evaluation, in this rule evaluation the defined rules are being compared with the input variables, further for every consecutive action the fuzzified output is generated. The final step of this process deals with the defuzzification. The most used method of defuzzification is centroid method. The defuzzification is an output value generated is removing the crisp data from it. The membership function is matched according to the respective output in an effective manner.

The main advantage of fuzzy logic control is no requirement of the exact model of the system. [10, 11]. The maximum power point tracking done by conventional system is little complex with mathematical models and it takes little longer response time. The inputs of the Fuzzy logic control are variable voltage in PV panel $(\Delta V)$ and variable power $(\Delta P)$. The fuzzy levels are declared for output and input variables are given as positive big, positive small, negative big, negative small. It is represented as

$$
\begin{aligned}
& \Delta V=V(K)-V(K-1) \\
& \Delta P=P(K)-P(K-1)
\end{aligned}
$$

In this fuzzy logic system various rules are framed with the base of voltage and power of the PV and hence the temperature is kept constant at $25^{\circ}$. In this condition the MPPT can be perfectly implemented and duty cycle is generated.

\begin{tabular}{|c|c|c|c|c|c|}
\hline NB & NB & NS & NULL & PS & PB \\
\hline NB & PB & PS & NB & NS & NS \\
\hline NS & PS & PS & NB & NS & NS \\
\hline $\begin{array}{c}\text { NULL } \\
Z\end{array}$ & NS & NS & NS & PB & PB \\
\hline PS & NS & PB & PS & NB & PB \\
\hline PB & NB & NB & PB & PS & PB \\
\hline
\end{tabular}

Table 2 Rules for Fuzzy logic Algorithm

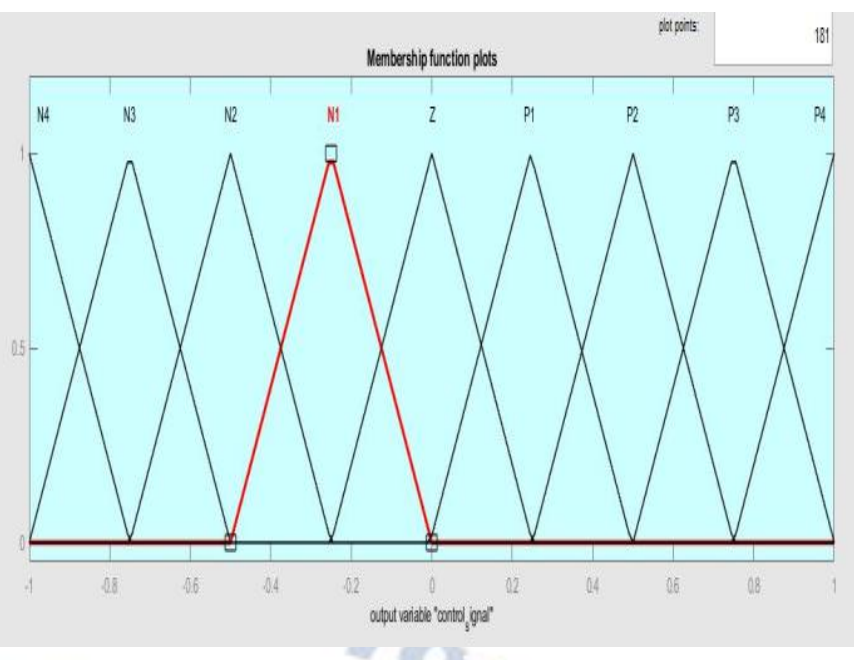

Fig 2 Membership function Plot

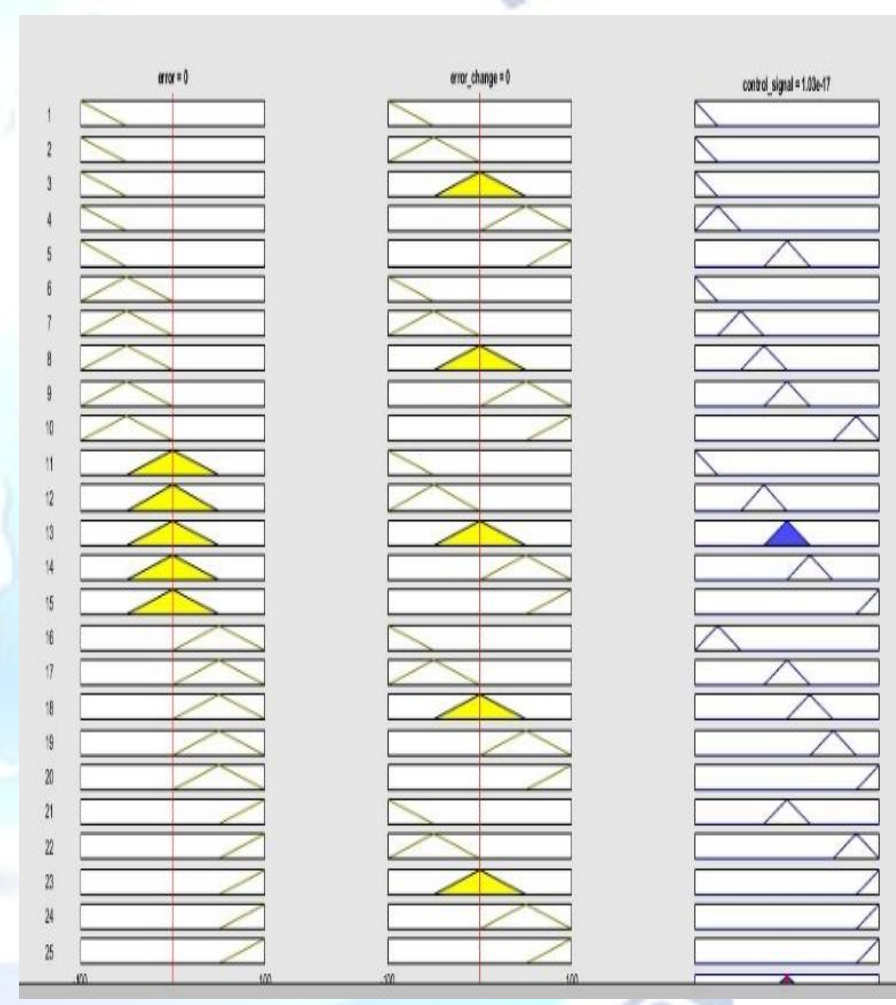

Fig 3 Generation of duty cycle with rule.

\section{Energy storage of the standalone system}

Energy storage is the most important feature in the stand-alone systems. Renewable energy sources like solar, Piezo-electric, Thermo electric generator (TEG) will provide nonlinear and directly depending on the various condition and the output is variable. Hence the requirement of energy storage is required to satisfy the load. The electrical energy storage devices are variously classified according to the application like grid energy storage system, portable electronics storage system, energy storage for transportation technology etc. The various types of batteries such as Sodium-ion, Lithium-ion, Lithium-polymer, Nickel-metal hydride, Nickel-cadmium, and lead 
acid batteries are widely used. In this work the generic battery model has been selected from Mat lab/Simulink and typical charge characteristics and other parameters are set according to the requirement.

The parameters of the battery in Mat lab/Simulink are tabled below

\begin{tabular}{|l|l|}
\hline PARAMETER & SPECIFICATION \\
\hline Nominal Voltage & 12 \\
\hline Rated Capacity & $50 \mathrm{Ah}$ \\
\hline Maximum Capacity & $70 \mathrm{Ah}$ \\
\hline Internal resistance & 1.02 Ohms \\
\hline Chemical composition & Lithium-Ion \\
\hline
\end{tabular}

Table 3 Parameters of battery capacity

\section{Basic design of SEPIC converter}

A SEPIC converter is similar to a traditional buck-boost converter but has advantages of having non inverted output. It has the same voltage polarity as the input, by using a series capacitor to couple energy from the input to the output and being capable of true shutdown [4]. The basic diagram of SEPIC converter is shown below

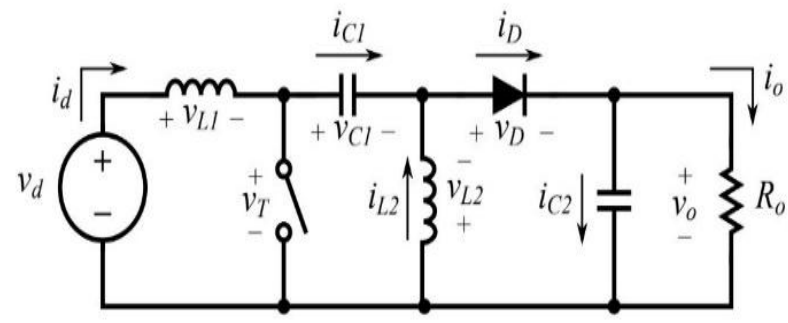

Fig 4: Circuit diagram of SEPIC Converter

The converter has the initial inductor hence it is capable of operating as buck and boost converter. The inductor and capacitor values are selected according to various parameters like Duty cycle, inductor ripple ratio and ESR of the capacitor. As every converter has different modes of operation the SEPIC converter also has two modes of operation, namely discontinuous conduction mode and continuous conduction mode. The Inductor and capacitor values are calculated with keeping various parameters of converters like Switching frequency $f_{s}$, Input voltage $V_{\text {in }}$, Output voltage $V_{\text {out }}$, Ripple current $\Delta$, In this theme the basic SEPIC converter is slightly modified by adding some additional switches and diodes for obtaining the dual input and dual output. The appropriate condition of selection of inductor would be considering the peak to peak ripple current to be nearly $40 \%$ of maximum ripple current at minimum voltage.

Hence according to the above stating of ripple current the inductor equation is given below

$\Delta I_{L}=I_{I N} \times 40 \%=I_{\text {OUT }} \times \frac{V_{\text {OUT }}}{V_{I N}(M I N)} \times 40 \%$

From the above equation, the inductor value is calculated by

$L 1=L 2=L=\frac{V_{I N(M I N)}}{\Delta I_{L} \times f_{S W}} \times D_{M A X}$

$f_{s w}-$ Switching frequency,

$\mathrm{D}_{\max }-$ Duty cycle at minimum $\mathrm{V}_{\text {in }}$

The equation of peak current in the inductor to check the inductor does not saturate, is given below

$$
\begin{aligned}
& I L_{1 \text { (PEAK) }}=I_{\text {OUT }} \times \frac{V_{\text {OUT }}+V_{D}}{V_{I N(M I N)}} \times\left(1+\frac{40 \%}{2}\right) \\
& I L_{2 \text { (PEAK) }}=I_{\text {OUT }} \times\left(1+\frac{40 \%}{2}\right)
\end{aligned}
$$

Output capacitor selection must undergo consideration of the handling maximum rms current. The output current is supplied by the end capacitor hence it should have the capability of sustaining the maximum rms current. The RMS current in the output capacitor is given by the equation below,

$$
I_{C \text { OUT }(r m s)}=I_{\text {OUT }} \times \sqrt{\frac{V_{\text {OUT }}+V_{D}}{V_{I N}(M I N)}}
$$

The ESR value is calculated by the

$$
E S R \leq \frac{V_{R I P P L E} \times 0.5}{I_{L 1(P E A K)} \times I_{L 2(P E A K)}}
$$

Diodes in the SEPIC converter should handle the peak current the equation is given as

$$
V_{R D 1}=V_{I N(M A X)}+V_{\text {OUT }(M A X)}
$$

E. Various modes of operation of customized sepic converter

The SEPIC converter is modified by implementing additional switches to achieve dual input and dual output actions. The output power from the solar source is taken as the reference for the load sharing technique. The power modulator diagram is given below in the figure (). The modes of operation are

- Dual Input Boost Mode

- Dual Output Boost Mode 
The modes of operation are achieved by implementing Load sharing control technique.

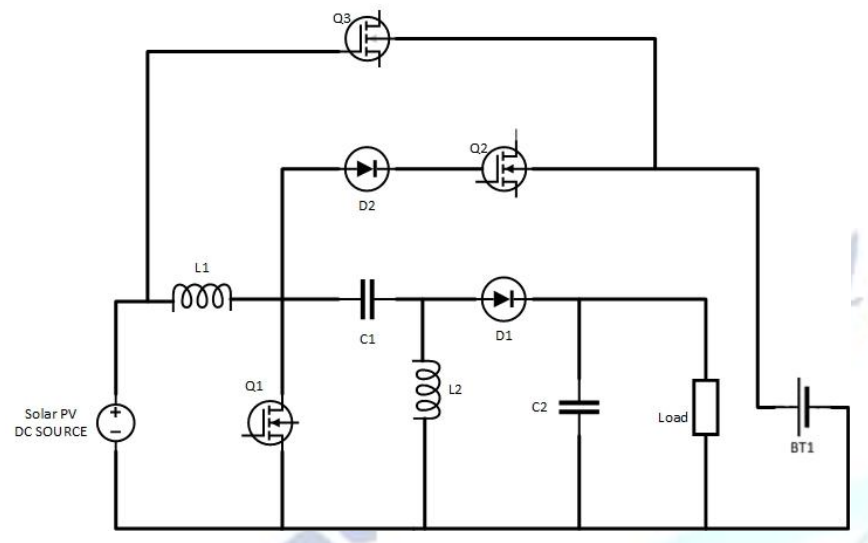

Fig 5. Circuit of SEPIC converter for implementing load sharing algorithm

Dual Input Boost Mode:

The solar power is variable and the deficit power is experienced at some instants. At that instant of deficit power from the source the converter should satisfy the demand to the load. This is achieved by the controlling the duty cycle from the fuzzy logic MPPT, and the switches are operated accordingly. This is expressed by the Ppv $<\mathrm{P}$ demand of the load -P battery (satisfies the load demand)

$$
V_{P V}=V_{O} \times D_{D 1 I N}+V_{b a t} D_{S 2}
$$

Here $\mathrm{S} 1$ and $\mathrm{S} 3$ are switched $\mathrm{ON}$, The $\mathrm{S} 1$ is switched on for the charging the inductor and following to that S3 is switched on to ensure the deficit power is satisfied by withdrawing the power from the battery. The duty cycle is altered by subtracting $d_{\text {Sboost }}$ with din then by dividing $d_{\text {Sboost }}$. The circuit flow is given below

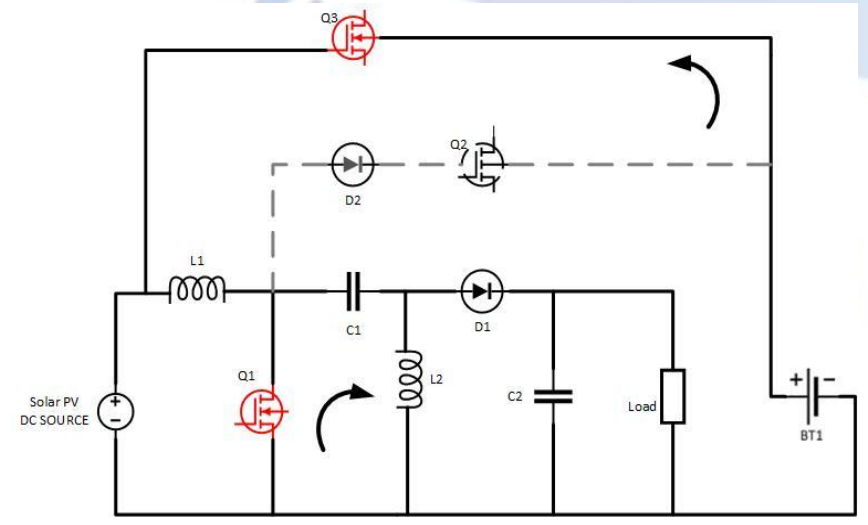

Fig 6. Circuit representing the switches $\mathrm{S} 1$ and $\mathrm{S} 3$ is ON state for charging Surplus power from source.
Dual Output Boost Mode:

In some conditions, after satisfying the load demand some excess power is generated, the power is considered as surplus power, the surplus power is utilized by storing it in a battery. The switch $\mathrm{S}_{2}$ is used to direct the power to the battery and $\mathrm{S}_{1}$ is used to provide the power to the load. In this mode the load is satisfied and battery is charged using surplus power from the availability of power from solar. This is expressed by the Ppv $>$ P demand. The below equation is very similar to the

$$
V_{P V}=V_{O} \times D_{D 3 I N}+V_{b a t} D_{S 1}
$$

The circuit flow is represented in below figure

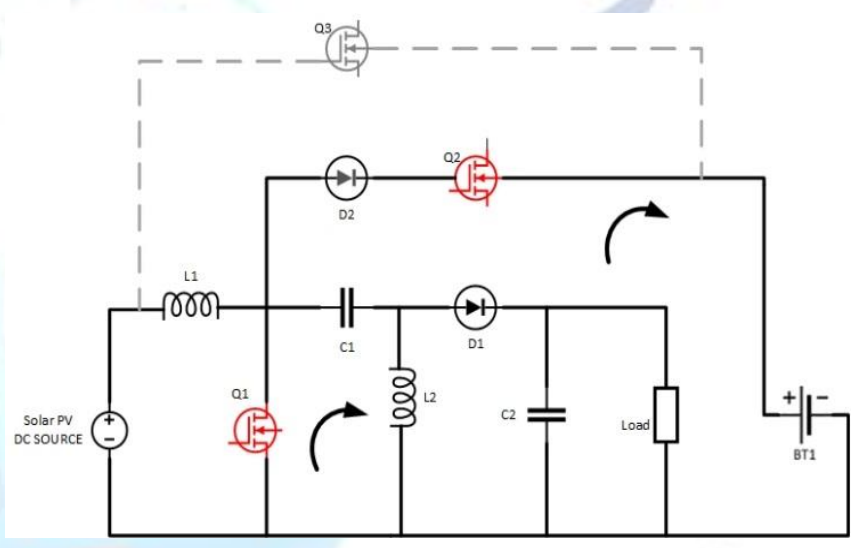

Fig 7. Circuit representing the switches $\mathrm{S} 1$ and $\mathrm{S} 2$ is $\mathrm{ON}$ state for charging Surplus power from source.

The dynamic power distribution logic / control logic is used in the circuit for harvesting the power to the maximum. These two modes are totally controlled by the load sharing logic that is implemented. The control logic is applied to the duty cycle from the fuzzy logic algorithm and given to three switches. This mode of operation is repeated for various input voltages. Further, analysis of load sharing, Stability is done using MATLAB/Simulink. The Logic is implemented in Real-time Simulation and the duty cycle is obtained.

\section{REAL TIME SIMULATION RESULTS}

The proposed SEPIC converter with Fuzzy based MPPT is simulated by implementing the Load sharing logic in MATLAB/Simulink platform. The passive elements are designed considering various parameters and the values are used for simulation. The values of the elements used are $150 \mu \mathrm{H}$ and $100 \mu \mathrm{F}$ for input coupling capacitor and load end 
capacitor $\mathrm{C}_{0}$. A $60 \mathrm{~W}$ solar panel is with maximum voltage of $25 \mathrm{~V}$ DC and battery with $6 \mathrm{~V} \& 12 \mathrm{~V}$ respectively. The Fuzzy-logic MPPT gives the output as duty cycle. The duty cycle is then processed with Load sharing control logic and that duty pulse is given to the switches. According to the power availability from the solar panel the switch operation is decided. This is achieved by various conditions of operations like deficit of power from the solar and Surplus power when the load consumes less power or no power at all. The MPPT control decides the total on time of switch and pole voltages.

The time-sharing control unit directs the power that to be distributed among the loads according to the availability of power from solar. The simulation of the total system is displayed in Fig 8. The process is achieved by operating the SEPIC converter in Dual Input Boost mode and Dual output Boost mode. The modes are charging the battery when there is surplus power and other mode is satisfying the load by battery.

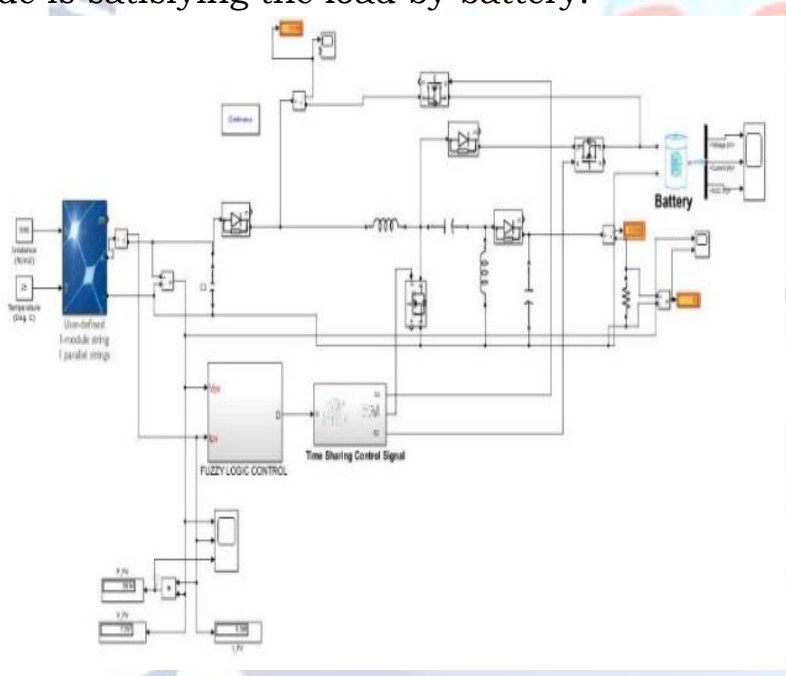

Fig 8. Simulation diagram of system

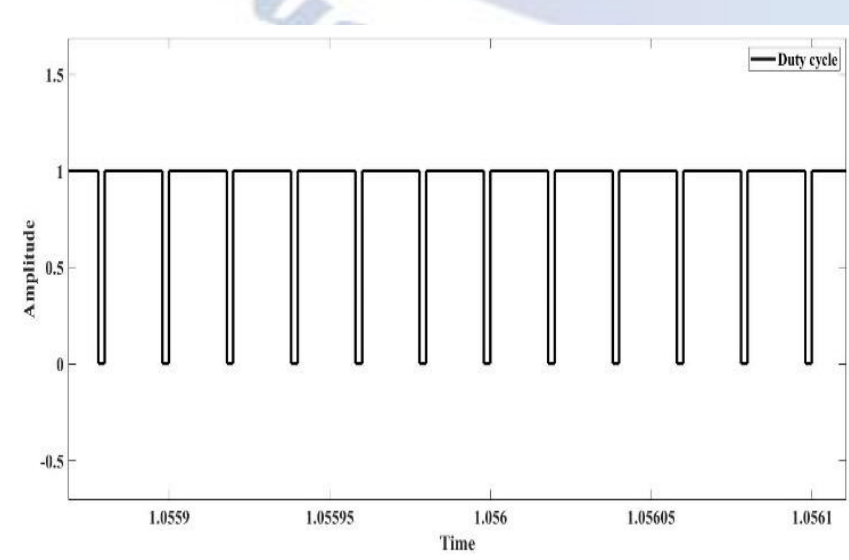

Fig 9. Duty cycle generation from MPPT
Mode 1: Increased solar power

When the power from the solar is about $20 \mathrm{~W}$. The Fuzzy logic MPPT generates duty cycle to extract the maximum power from it, and deficit power of $15 \mathrm{~W}$ is supplied by the Battery through the converter. This condition is Dual Input Boost Mode. When the power from the solar is increased to $30 \mathrm{~W}$ due to the insolation increase the solar power is capable of satisfying the load demand by decreasing the contribution of battery power to $5 \mathrm{~W}$. The condition is given in eqn.9 to satisfy the load constantly by reducing the support of a battery.

Mode 2: Switchover from Dual Input Boost Mode to Dual Output Boost Mode: In this condition, when the solar power is increased due to some increase in insolation, the load is satisfied by the solar power itself at that instant the MPPT generates duty cycle to extract maximum power from the solar, and the duty cycle will be $\mathrm{ds}_{\text {boost }}=\mathrm{d}_{\mathrm{MPPT}}$. This operation routes the surplus power to the battery. Now, the load demand is satisfied and surplus power is harvested in battery. In DOBM mode, switches $\mathrm{S} 1$ and $\mathrm{S} 2$ are operated. The $\mathrm{S} 1$ is to route the power to load and $\mathrm{s} 2$ is charge the battery. The control logic will reduce the duty cycle to S1 and increases the S2 duty cycle to charge the battery. Hence the control logic smoothly converts the Dual Input Boost Mode to Dual Output Boost mode. The control logic is shown in fig (12).

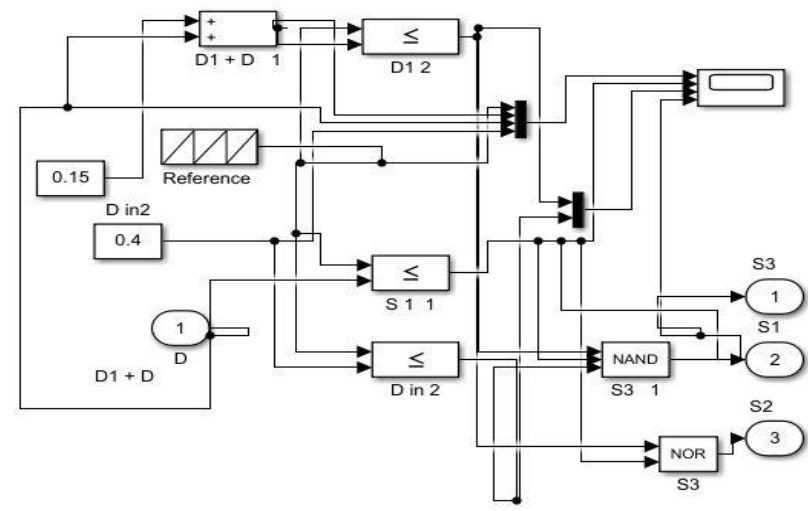

Fig 10. Control logic 

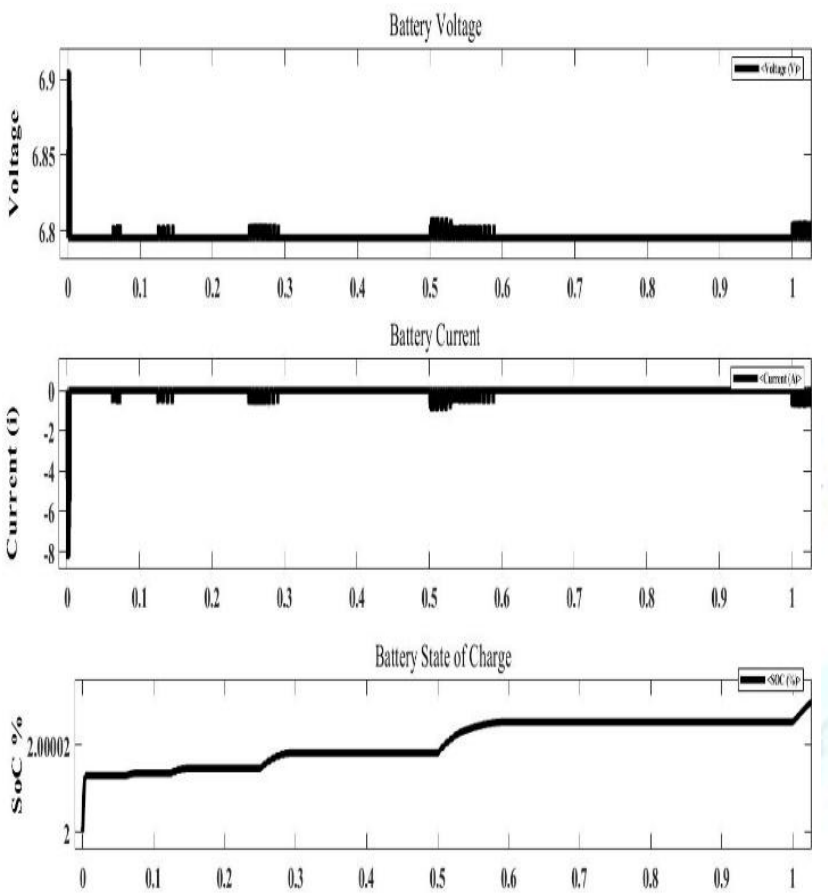

Fig 11. Dual Input boot mode i) Battery charging ii) satisfying load demand

Mode 3: Switchover from Dual Output Boost Mode to Dual Input Boost Mode: The power output from the solar will reduce when the insolation reduces.at that time instant, load will experience deficit of power. Now the control logic will change the base MPP to new MPP of S1 to maximize the solar power extraction and the converter will consider battery as the input source. Now to make use of battery power, the battery is given as another input to the converter. This is achieved by providing duty cycle to the Switch S3, so that the power from the battery is given as input to the converter. The battery discharging is shown in fig 12 now the load demand is satisfied by battery and solar.
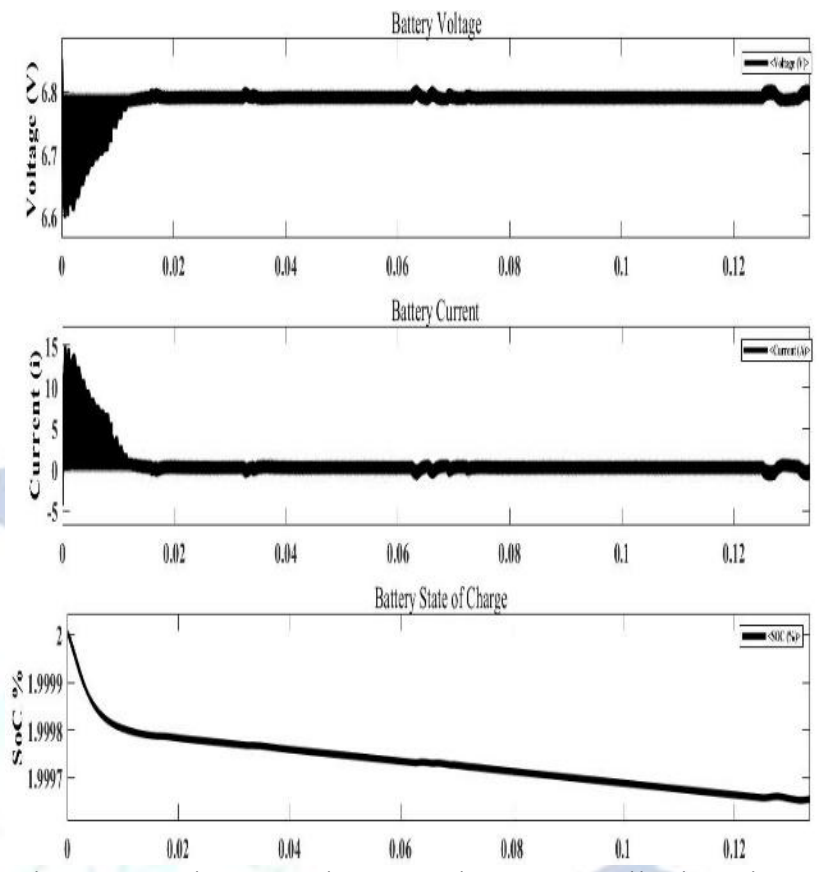

Fig 12. Dual output boot mode-Battery discharging to satisfy load demand

The converter with control logic is simulated with various power levels for the load. The various values are tabulated in table 4 . This proves the system is very efficient for standalone system. The simulation is done with control logic in real-time simulator OPAL-RT and the duty cycle is generated.

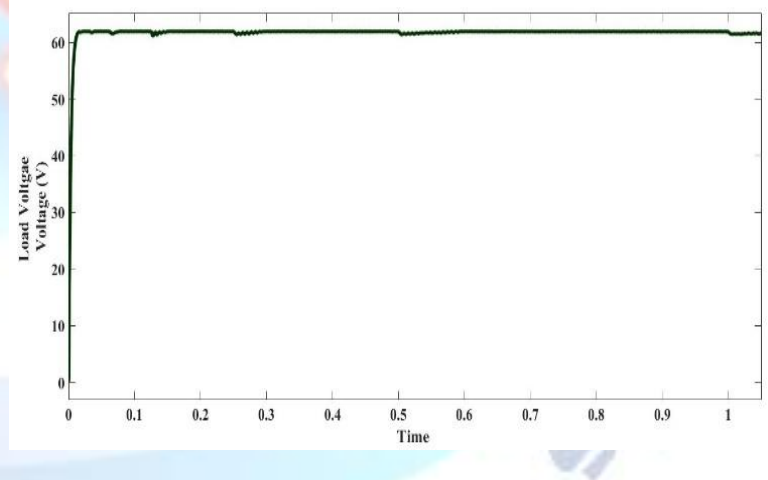

Fig 13. Load Voltage

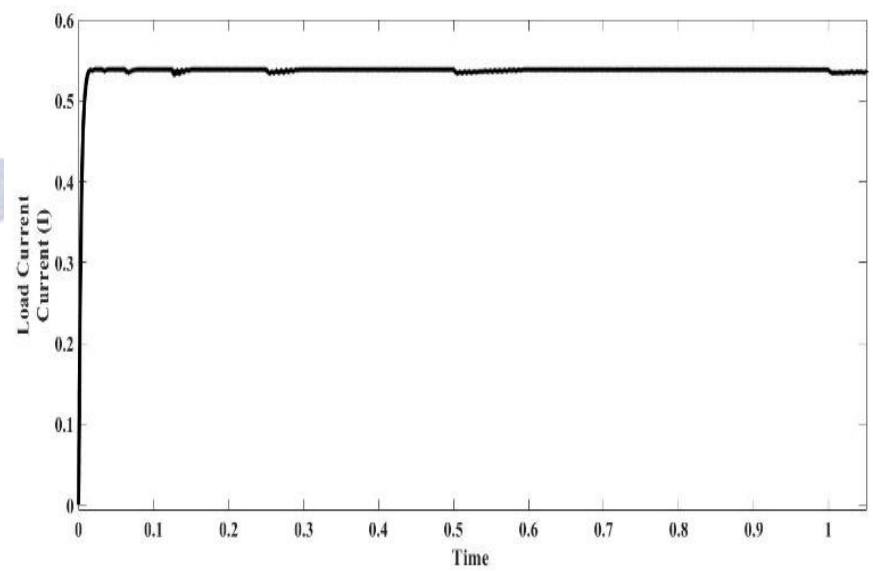

Fig 14. Load Current 


\section{Conclusion}

The power sharing technique in standalone system with battery backup is exhibited with SEPIC DC-DC converter and fuzzy based MPPT for solar power source. A control logic technique for regulating the power is implemented in this system to harvest the additional power available. The system is capable of supporting autonomous system without any interruption to the load. Therefore, energy harvested when the surplus energy is available and stored energy is utilized to satisfy the load demand when there is insufficiency of power from solar. Extraction of maximum power from solar has many methods, but while comparing fuzzy logic helps in improving the stability [9]. According to the demand and power availability the battery can be installed. For many sensitive systems which needs more information of stability, a battery system may be installed with the battery power monitoring system. The system helps in most important autonomous system like IOT devices, defense applications, medical applications, portable and so on. In the future the system will be developed in hardware and verified experimentally.

Table 2 Result

\begin{tabular}{|c|c|c|c|c|c|c|c|c|c|}
\hline $\mathrm{V}_{\mathrm{pv}}$ & $\mathrm{I}_{\mathrm{pv}}$ & $\mathrm{P}_{\mathrm{pv}}(\mathrm{W})$ & $\mathrm{V}_{\text {bat }}$ & $\mathrm{I}_{\text {bat }}$ & $\mathrm{P}_{\text {bat }}$ & $\mathrm{V}_{\mathrm{L}}$ & $\mathrm{I}_{\mathrm{L}}$ & $\mathrm{P}_{\mathrm{L}}$ & Mode \\
\hline 9 & 2 & 18 & 8 & 3 & 24 & 59.92 & 0.5 & 30 & DIB \\
\hline 3 & 1.8 & 5.4 & 8 & 3.4 & 25.6 & 61.08 & 0.47 & 31.2 & DIB \\
\hline 11 & 3.4 & 37.4 & 10 & -0.59 & -5.9 & 56 & 0.54 & 30.24 & DOB \\
\hline 10 & 3.9 & 39 & 8.9 & -0.946 & -8.41 & 60 & 0.5 & 30 & DOB \\
\hline 2 & 1 & 2 & 7 & 3.87 & 27.09 & 54 & 0.55 & 29.7 & DIB \\
\hline
\end{tabular}

\section{REFERENCES}

[1] Mr. Vaibhav R.Pannase, Prof.H.B.Nanavala A Review of PV Technology Power Generation, PV Material, Performance and its Applications International Conference on Inventive Systems and Control (ICISC-2017)

[2] GAGA Ahmed, ERRAHIMI Fatima, ES-SBAI Najia Design and implementation of MPPT solar system based on the enhanced $\mathrm{P} \& \mathrm{O}$ algorithm using Labview, 978-1-4799-7336-1/14/ 2014 IEEE

[3] S. Sheik Mohammed, D. Devaraj, T. P. Imthias Ahamed, Maximum Power Point Tracking System for Stand Alone Solar PV Power System Using Adaptive Neuro-Fuzzy Inference System 2016 Bienniallnternationa Conference on Power and Energy Systems: Towards Sustainable Energy (PESTSE)

[4] Basil M. Hamed, Mohammed S. El-Moghany, Fuzzy Controller Design Using FPGA for Photovoltaic Maximum Power Point Tracking (IJARAI) International Journal of Advanced Research in Artificial Intelligence, Vol. 1, No. 3, 2012

[5] V. Ramanarayanan, Course Material On Switched Mode Power Conversion December 2, 2007

[6] [6] Robert W. Erickson Fundamentals of power electronics, second edition.

[7] R. P. Massey and E. C. Snyder."High Voltage Single-Ended DC-DC Convertor".1977 IEEE PESC Record pp 156-159.

[8] J. Rahulkumar and K. RanjithKumar, "Efficient Utilization of Renewable Energy Employing SEPIC Converter for Standalone Solar PV System," 2019 5th International Conference on Advanced Computing \& Communication Systems (ICACCS), Coimbatore, India, 2019, pp. 1083-1088, doi: 10.1109/ICACCS.2019.8728436.

[9] Anand I, Subramaniam Senthilkumar, Dipankar Biswas and M. Kaliamoorthy, Feb 2018, "Dynamic PowerManagement System Employing Single Stage Power Converter for Standalone Solar PV Applications", IEEE Transactions on Power Electronics.
[10] K.Prasanna,

Dutta ruothDr.D.Kirubakaran, J.Rahulkumar, J.A. Rudhran International Research Journal of Engineering and Technology (IRJET) Volume: 02 Issue: 03 | June-2015 e-ISSN: 2395-0056, p-ISSN: 2395-0072.

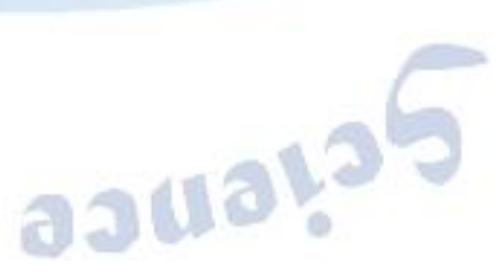

